COLON CANCER

\title{
Familial adenomatous polyposis patients without an identified $A P C$ germline mutation have a severe phenotype
}

\author{
M L Bisgaard, R Ripa, A L Knudsen, S Bülow
}

Gut 2004;53:266-270

See end of article for authors' affiliations .....................

Correspondence to: Dr M L Bisgaard, The Danish Polyposis Register, Department of Surgical Gastroenterology 435, Hvidovre University Hospital, Kettegaard Alle 30, DK-2650 Hvidovre, Denmark; ml.bisgaard@ get2net.dk

Accepted for publication 20 August 2003
Background: Development of more than 100 colorectal adenomas is diagnostic of the dominantly inherited autosomal disease familial adenomatous polyposis (FAP). Germline mutations can be identified in the adenomatous polyposis coli (APC) gene in approximately $80 \%$ of patients. The APC protein comprises several regions and domains for interaction with other proteins, and specific clinical manifestations are associated with the mutation assignment to one of these regions or domains.

Aims: The phenotype in patients without an identified causative APC mutation was compared with the phenotype in patients with a known APC mutation and with the phenotypes characteristic of patients with mutations in specific $A P C$ regions and domains.

Patients: Data on 121 FAP probands and 149 call up patients from 70 different families were extracted from the Danish Polyposis register.

Methods: Differences in 16 clinical manifestations were analysed according to the patient's mutational status. Two sided independent $t$ sample test, two sided $\chi^{2}$ test, and odds ratios were calculated.

Results: Patients without identified APC mutations had a unique and severe phenotype, which was roughly described as: young age at diagnosis and subsequent death in spite of development of few colorectal adenomas; low risk of involvement of the upper gastrointestinal tract, as reflected by a low mean Spigelman stage, and a low risk of fundic gland polyposis. Finally, they had significantly fewer affected family members, although they do not themselves more often represent an isolated case.

Conclusions: The severe phenotype should be considered when counselling FAP families in which attenuated FAP is excluded and in which a causative APC mutation has not been identified.
$\mathrm{F}$ amilial adenomatous polyposis (FAP) (MIM 175100) is a dominantly inherited disease characterised by the development of 100 to several thousand colorectal adenomas that, if untreated, will inevitably result in one or several colorectal cancers. The upper gastrointestinal tract is frequently involved, with polyps and adenomas of the stomach and duodenum; these adenomas also occasionally become malignant. ${ }^{1}$ Desmoid tumours (infiltrative fibromatosis) are the most serious of the FAP features found outside the intestinal system because of a tendency to invade locally. ${ }^{2}$ Furthermore, FAP is characterised by congenital hypertrophy of the retinal pigment epithelium, osteomas, and sebaceous cysts (epidermoid cysts). ${ }^{3}$ The adenomatous polyposis coli gene $(A P C)$ was localised on chromosome 5 in $1987^{4}$ and identified in 1991, ${ }^{5}$ opening the way for molecular genetic diagnosis. Among all FAP patients, $20-25 \%$ are the result of de novo mutations, ${ }^{6}$ which is reflected in the large proportion of FAP families with only one affected member (known as isolated cases). The APC gene is described as a gatekeeper because mutations in the gene initiate adenoma development and subsequent progression into colorectal cancer by disturbance of proliferation regulation of colonic cells. ${ }^{78}$

The APC protein comprises regions and domains allowing for various protein interactions and some phenotypes are most frequently found in patients with germline mutations in particular domains.

Little has been published on the approximately $20 \%$ of FAP patients in whom a pathogenic mutation is not identified in the APC gene. The FAP diagnosis has previously often wrongly been excluded in families in which an $A P C$ mutation could not be identified, with the consequence of termination of surveillance programmes. ${ }^{9}$ In these families, genetic testing cannot be offered and all family members at risk should be encouraged to follow surveillance programmes.
The objective of this study was primarily to characterise the phenotypic traits in FAP patients without an identified APC germline mutation, and to compare this phenotype with phenotypes characteristic of patients with mutations in specific $A P C$ gene domains

\section{MATERIAL AND METHODS}

\section{Patients and families}

Data from 70 families with completed mutation analysis of the APC gene, comprising a total of 270 patients diagnosed with FAP, were extracted from the Danish Polyposis Register and analysed for phenotype-genotype correlations. The diagnostic criteria for patients registered in the Danish Polyposis register were: (1) 100 or more colorectal adenomas or (2) a family history of FAP and nearly 100 colorectal adenomas (or more) or (3) a truncating APC germline mutation. Of the 270 affected family members, the probands accounted for 121 and call up patients 149 .

\section{Phenotypic traits}

At the outset, analysis was carried out to examine for phenotypic differences between patients from families with $(\mathrm{n}=218)$ and without $(\mathrm{n}=52)$ a mutation identified in the $A P C$ gene. Next, the phenotype found in patients without an identified mutation was compared with the phenotypes characteristic for patients with mutation in two of the functional $A P C$ regions or domains: colorectal cancer mutation cluster region (CRC-MCR), codon 1251-1455 ( $\mathrm{n}=32$ )

\footnotetext{
Abbreviations: FAP, familial adenomatous polyposis; APC, adenomatous polyposis coli gene; CRC-MCR, colorectal cancer mutation cluster region; MAMA, monoallelic mutation analysis
} 
and post-colorectal cancer mutation cluster region (postCRC-MCR), after codon $1456 \quad(n=22) \quad$ (modified from Groves and colleagues). ${ }^{10}$ The phenotypic traits included number of affected family members per family; age at diagnosis of FAP; number of colorectal adenomas counted in operation specimens; presence of CRC; age at diagnosis of CRC; and age at death. Call up patients were also analysed for age at adenoma development and probands were analysed for age at symptom development. Patients were also assessed for the presence of extracolonic features such as epidermoid cysts, mandibular and clinical recognisable osteomas, and desmoid tumours. A subset of patients $(\mathrm{n}=84)$ had participated in the collaborative study Duodenal Adenomatosis in Familial Adenomatous Polyposis (DAF). ${ }^{1}$ These patients were also analysed for the presence or absence of fundic gland polyposis, duodenal adenomas, and for differences in mean values of their Spiegelman stage (see tables 1 and 2 for the list of variables analysed).

\section{Mutation analysis}

DNA extraction and mutation analysis were performed using standard procedures, as previously described. ${ }^{11}$

\section{Statistical analysis}

Differences in age at adenoma development, symptoms, diagnosis of CRC, diagnosis of FAP, and death, and differences in number of affected per family were analysed using a two sided independent $t$ sample test. The presence of CRC and extracolonic features were tested using a two sided $\chi^{2}$ test, and odds ratios were calculated to estimate risk. The data sets were separated into three groups ("positive", "negative", and "unknown") and calculations were performed on "positive" and "negative" values, except for information on epidermoid cysts and clinical osteomas for which the groups of "negative" and "unknown" were pooled into one group, and calculations performed using these two groups. Level of significance was set at 0.05

\section{RESULTS}

\section{Phenotypic differences between affected patients} without and with an identified mutation

In order to characterise patients with an FAP diagnosis but without a mutation identifiable by PTT and sequencing of the $A P C$ gene, 16 different phenotypic traits were analysed and the differences between patients with and without mutations were compared. Affected patients without an identified mutation were characterised by having significantly fewer affected relatives (mean raw number of affected relatives 2.3 $v 4.6$ affected family members per family) but this was not because they more often were isolated cases-at least not at a statistically significant level (tables 1 and 2, first column). They tended to be younger when their first FAP symptoms appeared ( 31.2 years versus 36.3 years) and accordingly had a low mean age at death (39.6 years $v 47.4$ years). Call up patients from families without an identified mutation seemed to be 10 years older (mean 31.6 years $v 21.3$ years) when developing adenomas, which was in accordance with rarely finding more than 1000 adenomas in the colon specimen of probands from this group (odds 0.27). Involvement of the upper gastrointestinal tract was significantly less frequent, as reflected by a lower Spigelman stage $(0.50 v 1.35)$. Fundic gland polyposis (odds 0.30) and duodenal adenomas (odds 0.24) were consequently less frequently found in these patients. Other extraintestinal traits such as mandibular osteomas, epidermoid cysts, and desmoid tumours were found in both groups of patients. This was however not the case for the few osteomas registered, with localisation other than the mandible, as the latter were only found in FAP patients with a known APC mutation. Results are listed in tables 1 and 2.

\section{Phenotypic characteristics for FAP patients without an identified mutation compared with phenotypes characteristic for specific $A P C$ domains}

The phenotype that was found to be characteristic of patients without an identified APC mutation was analysed for points of resemblance with the phenotypes characteristic for patients having mutations in the functional domains CRC-MCR

Table 1 Comparison of phenotypes between the genotype "APC mutation not identified" and the genotypes "mutation identified in the CRC-MCR domain" and "mutation identified in the post-CRC-MCR domain

\begin{tabular}{|c|c|c|c|c|c|c|c|c|c|c|}
\hline \multirow[b]{3}{*}{ Phenotype } & & \multicolumn{9}{|c|}{ Genotype } \\
\hline & & \multicolumn{3}{|c|}{$\overline{A P C}$ mutation identified? } & \multicolumn{3}{|c|}{ Mutation in CRC-MCR domain? } & \multicolumn{3}{|c|}{ Mutation in post-CRC-MCR domain? } \\
\hline & & Yes & No & p Value & Yes & No & p Value & Yes & No & p Value \\
\hline \multirow{4}{*}{$\begin{array}{l}\text { Mean No of affected } \\
\text { persons in the families } \\
\text { Age at colon adenoma } \\
\text { development }(y)^{*}\end{array}$} & $\mathrm{n}$ & 48 & 22 & & 9 & 39 & & 4 & 44 & \\
\hline & Mean & 4.6 & $2.3 \S$ & 0.02 & $3.6 \S$ & 4.8 & NS & $5.5 \pm \ddagger$ & 4.5 & NS \\
\hline & $\mathrm{n}$ & 33 & 4 & & 3 & 30 & & $3^{3++}$ & 30 & \\
\hline & Mean & 21.3 & $31.6 \ddagger$ & 0.09 & $8.4 \S \S$ & 22.7 & 0.02 & $32.6 \neq$ & 20.2 & NS \\
\hline \multirow[t]{2}{*}{ Age at symptoms $(y) \dagger$} & $\mathrm{n}$ & 71 & 28 & & 16 & 55 & & 4 & 67 & \\
\hline & Mean & 36.3 & $31.2 \S$ & 0.08 & $28.1 \S$ & 38.7 & 0.00 & $43.2 \pm \ddagger$ & 35.9 & NS \\
\hline \multirow{2}{*}{$\begin{array}{l}\text { Age at diagnosis of CRC } \\
\text { (y) }\end{array}$} & $\mathrm{n}$ & 56 & 19 & & 10 & 46 & & 1 & 55 & \\
\hline & Mean & 42.7 & $40.1 \S$ & NS & $34.2 \S$ & 44.5 & 0.01 & $51.2 \neq \ddagger$ & 42.4 & NS \\
\hline \multirow{2}{*}{$\begin{array}{l}\text { Age at diagnosis of FAP } \\
(y) \dagger\end{array}$} & $\mathrm{n}$ & 88 & 2 & & 19 & 69 & & 5 & 83 & \\
\hline & Mean & 37.8 & $33.8 \S$ & NS & $30.4 \S$ & 39.8 & 0.00 & $42.7 \pm \ddagger$ & 37.5 & NS \\
\hline \multirow[t]{2}{*}{ Spigelman stage } & $\mathrm{n}$ & 66 & 16 & & 8 & 58 & & $10^{++}$ & 56 & \\
\hline & Mean & 1.35 & $0.50 \S$ & 0.01 & $1.50 \ddagger \ddagger$ & 1.33 & NS & $1.20 \S$ & 1.38 & NS \\
\hline \multirow[t]{2}{*}{ Age at death (y) } & $\mathrm{n}$ & 67 & 20 & & $12^{-0++}$ & 55 & & 3 & 64 & \\
\hline & Mean & 47.4 & $39.6 \S$ & 0.01 & $42.9 \S$ & 50.4 & NS & $59.3 \neq \ddagger$ & 48.2 & NS \\
\hline
\end{tabular}

FAP, familial adenomatous polyposis; APC, adenomatous polyposis coli gene; CRC-MCR, colorectal cancer mutation cluster region.

${ }^{*}$ Call up patients only.

†Probands only.

†The mean value for the trait was highest in patients without an identified mutation in APC or in those with a mutation identified either in the CRC-MCR domain or in the post-CRC-MCR domain.

$\S$ The mean value for the trait was lowest in patients without an identified mutation in APC or in those with a mutation identified either in the CRC-MCR domain or in the post-CRC-MCR domain.

Single symbols ( $\ddagger$ or $\S$ ) indicate when the tendency was the same as for patients without an identified mutation, and double symbols ( $¥ \ddagger$ or $\S \S$ ) when different. 
Table 2 Odds ratio for finding the listed traits in affected persons with regard to mutational status

\begin{tabular}{|c|c|c|c|c|c|c|c|c|c|}
\hline \multirow[b]{3}{*}{ Phenotype } & \multicolumn{9}{|c|}{ Genotype } \\
\hline & \multicolumn{3}{|c|}{ APC mutation identified? No $v$ yes } & \multicolumn{3}{|c|}{ Mutation in CRC-MCR domain? Yes $v$ no } & \multicolumn{3}{|c|}{$\begin{array}{l}\text { Mutation in post CRC-MCR domain? } \\
\text { Yes } v \text { no }\end{array}$} \\
\hline & $\mathrm{n}^{*}$ & Odds ratio & p Value & $\mathrm{n}^{*}$ & Odds ratio & p Value & $\mathrm{n}^{*}$ & Odds ratio & p Value \\
\hline Family with isolated case & 70 & $1.86 \ddagger$ & NS & 48 & $4.84 \ddagger$ & 0.03 & 48 & $3.00 \ddagger$ & NS \\
\hline Epidermoid cysts & 270 & $0.72 \S$ & NS & 218 & $2.69 \pm \ddagger$ & 0.07 & 218 & $2.05 \ddagger \ddagger$ & NS \\
\hline Osteomas & 270 & $* \star \S$ & NS & 218 & 0.99 & NS & 218 & $7.58+\ddagger$ & 0.00 \\
\hline Mandibular osteomas & 65 & $0.32 \S$ & 0.08 & 53 & $1.83 \neq \ddagger$ & NS & 53 & ***$\ddagger \ddagger$ & NS \\
\hline Desmoids & 233 & $1.08 \ddagger$ & NS & 184 & $* * \star \star \S \S$ & NS & 184 & $4.46 \ddagger$ & 0.01 \\
\hline Colorectal cancer & 268 & $1.50 \ddagger$ & NS & 216 & $1.44 \ddagger$ & NS & 216 & $0.11 \S \S$ & 0.01 \\
\hline $\begin{array}{l}>1000 \text { colorectal } \\
\text { adenomas }\end{array}$ & 192 & $0.27 \S$ & 0.00 & 156 & $3.28 \neq \ddagger$ & 0.01 & 156 & $0.34 \S$ & NS \\
\hline Fundic gland polyposis & 84 & $0.30 \S$ & 0.05 & 66 & $0.60 \S$ & NS & 66 & 12.99 㧊 & 0.00 \\
\hline Duodenal adenomas & 82 & $0.24 \S$ & 0.01 & 66 & $1.14 \pm \ddagger$ & NS & 66 & $1.30 \pm \ddagger$ & NS \\
\hline \multicolumn{10}{|c|}{ 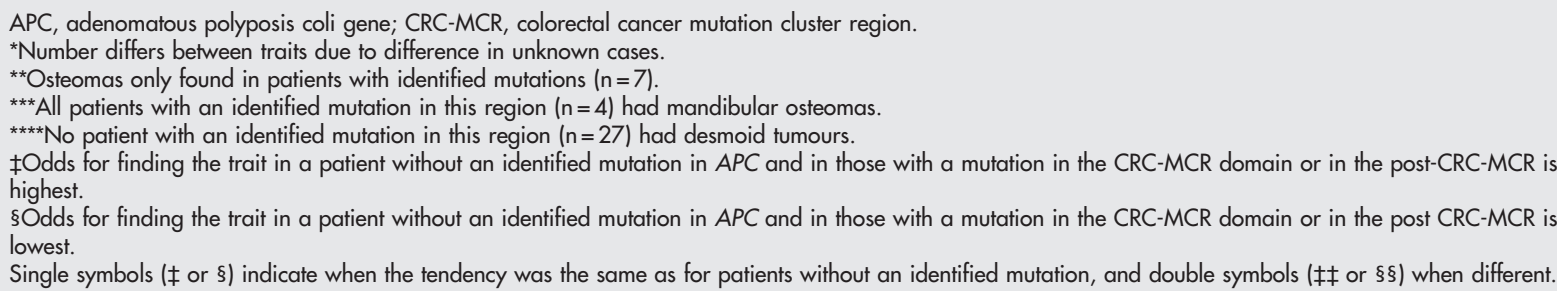 } \\
\hline
\end{tabular}

and post-CRC-MCR. Sixteen phenotypic traits were analysed with regard to each of these APC domains. The aggressive phenotype found in patients without an identified $A P C$ mutation was also found in patients with a mutation in the CRC-MCR: both had a young age at death (39.6 and 42.9 years). Furthermore, age at symptom development, FAP, and CRC diagnosis tended to be early. The two groups differed from each other in two associated traits: age at colorectal adenoma development for call up patients and number of adenomas. Call up patients with a mutation in the CRC-MCR domain were very young when they started to develop adenomas ( 8.4 years), and the risk of finding more than 1000 colorectal adenomas was significantly higher (odds ratio 3.28), while the opposite was true for affected patients without an identified APC mutation (31.6 years, odds ratio 0.27). Patients with a mutation in the CRC-MCR region did not differ significantly from patients with mutations in other APC domains when evaluated for involvement of the upper gastrointestinal tract while patients without an identified $A P C$ mutation had a significantly lower Spigelman stage $(0.50 v 0.35)$. With regard to these traits and age at adenoma development in call up patients, patients without an identified APC mutation tended to resemble patients with a mutation in the post CRC-MCR domain. Osteomas and desmoid tumours characterised the phenotype found in patients with a mutation in the post CRC-MCR domain while CRC was rare. The odds ratio for finding fundic gland polyposis was almost 13 in patients with a mutation in the post CRC-MCR domain compared with only 0.30 in patients without an identified mutation.

\section{Mutations}

Thirty six different mutations were identified in 48 families, leaving 22 families without an identified APC mutation. The mutation pattern, types, and localisation in the APC genes resembled what is generally found. ${ }^{11-13}$

\section{DISCUSSION}

Affected persons from families without an identified mutation differed in several phenotypic traits from their counterparts with an identified mutation; the phenotype of the former could be summarised as being very aggressive (the proband developed symptoms earlier in life and died very young, in spite of call up patients developing adenomas at more advanced ages). In accordance with young age at death, the raw number of affected relatives was low. If patients without an identified mutation had been isolated cases, it would have been tempting to explain absence of an APC mutation by misdiagnosis, but this seems unlikely as isolated FAP cases were not more frequently found in families without an identified mutation. In contrast, isolated cases were significantly more frequent in families with a mutation in the CRC-MCR region, which is known to harbour a mutational hotspot with an aggressive phenotype. ${ }^{14}{ }^{15}$ The number of colorectal adenomas was relatively low, and extracolonic manifestations such as osteomas, cancers, fundic gland polyposis, and duodenal adenomas were rare or absent (tables 1 and 2). Heinimann and colleagues ${ }^{16}$ performed a comparable analysis with a less comprehensive material and found two statistically significant differences between patients with and without an identified APC mutation. They found gastric polyps only in patients with an identified mutation, which was in accordance with our finding of upper gastrointestinal traits being rare in patients without an identified mutation. Surprisingly, Heinimann et al as well as Moisio and colleagues ${ }^{17}$ found age at FAP diagnosis more advanced in probands without an identified mutations (Heinimann $48.7 v 34.6$ years; Moisio $44.2 v 35.6$ years) while we found the opposite, although the difference was not statistically significant ( $33.8 v 37.8$ years). The disagreement could be due to differences in patient composition with regard to mutation distribution and accordingly differences in phenotype. Furthermore, the three studies had different diagnostic criteria. Thirty six patients in the Heinimann study were diagnosed with FAP based solely on a diagnosis of CRC, disregarding the lack of information on the number of adenomas. The presence of less than 100 adenomas was found more frequently in patients without an identified mutation, while the Danish patients were registered in the Polyposis Register-and included in this study-only if they had more than 100 adenomas or a family history of polyposis and approximately 100 adenomas (or more) or were diagnosed with a pathogenic mutation. These more strict criteria are not likely to allow for phenocopies but will tend to exclude FAP families with attenuated polyposis and late age at onset if a pathogenic mutation is not identified. The 
diagnostic criteria applied in the Moisio et al study were satisfied when 100 adenomas or more were found in just one family member but inclusion criteria for the other affected family members were not stated. This difference may explain why they found almost the same mean number of affected family members per kindred while in the present study we found that FAP families with an identified mutation had twice as many affected family members as families without an identified mutation.

Differences in phenotypes found in patients with and without an identified mutation indicate heterogeneity in polyposis or that masked $A P C$ mutations ${ }^{18}$ have a distinct phenotype, or perhaps both. Recently it was demonstrated that MYH mutations when present biallelic resulted in phenotypes indistinguishable from patients with monoallelic truncating APC mutations although the former tended to have fewer adenomas and a more advanced age at onset. ${ }^{19} 20$ A similar phenotype has been described by Stella et al in two families in which an APC mutation was excluded by linkage analysis. ${ }^{21}$ A phenotype with a few adenomas together with (1) an expected higher mean age at adenoma development for patients with relatively few adenomas and (2) the fact that disease caused by MYH mutations was inherited recessively and therefore generally will appear only in one generation, resulting in smaller number of affected members in the families, were in accordance with our findings for affected members without an APC mutation. However, at present, there is no evidence of MYH biallelic mutation carriers dying young. Sieber et al found that MYH biallelic mutations were responsible for disease in $6.6 \%$ of polyposis families without an APC mutation. ${ }^{20}$ Approximately half of our families without an identified $A P C$ mutation were included in their work and biallelic MYH mutations were identified in just one family comprising four affected members. Hence MYH mutations explain only a minor part of the missing APC mutations. Laken and colleagues ${ }^{18}$ found masked $A P C$ mutations in seven of nine FAP patients in whom an $A P C$ mutation was not identifiable by standard methods but were detectable after separating the maternal and paternal chromosome 5 and analysing one allele at a time. They concluded that more than $95 \%$ of patients with FAP have inactivating mutations in $A P C$; these mutations were either identifiable by standard methods (approximately $80 \%$ ) or by monoallelic mutation analysis (MAMA, approximately $15 \%$ ). The authors did not comment on the phenotype found in families with masked mutations and it must be kept in mind that the MAMA analysed material was small. It remains to be seen whether the MAMA phenotype fits our findings or, as a consequence, other genes or methods have to be taken into consideration. The sum of percentages extracted from the two studies (95\% plus 6.6\%) does add up to approximately $100 \%$, indicating that FAP is accounted for genetically by APC mutations identifiable by standard methods, MAMA, and MYH mutations. Results from the present study revealed a striking difference in phenotype for FAP patients without an identified APC mutation by standard methods, an important point in the genetic clinic when counselling patients and deciding on their surveillance programmes. The described phenotype had a resemblance to the phenotype found in patients with mutations in the CRC-MCR domain but was clearly not the same as they differed in several traits, particularly age at adenoma development and number of adenomas. It appeared that the relatively few adenomas found in patients without an identified APC mutation must have had a very high malignant potential as these patients died very young, a few years after the onset of symptoms. According to Lakens and colleagues ${ }^{18}$ it is likely that the majority of patients have a masked APC mutation, and it is our conclusion that these mutations must possess proliferative advantages compared with other $A P C$ mutations and facilitate fast malignant transformation. The exact mechanism remains to be investigated.

The phenotypes of the patients from the four families who harboured mutations in the post CRC-MCR domain demonstrated great variation, from classic polyposis to attenuated polyposis. The same was true for affected patients from families with mutations localised in domains different from CRC-MCR, as previously described.$^{22}$ A specific phenotype was most prominent in patients with a mutation in the CRCMCR region and those without an identified mutation. Aggressive phenotypes were found in patients from both groups, characterised by early death, young age at diagnosis, and low number of affected family members. As opposed to patients with a CRC-MCR mutation, patients without an identified mutation had a less colorectal adenoma burden and low involvement of the upper gastrointestinal tract.

In conclusion, FAP patients diagnosed with 100 or more adenomas but without an identified APC germline mutation have a unique severe phenotype characterised by young age at diagnosis and early age at death in spite of the development of relatively few adenomas. These characteristics have to be taken into consideration when counselling family members.

\section{ACKNOWLEDGEMENTS}

Kirsten Winther and Maria Polak are thanked for sample handling and preparation, and Vibeke Reichardt and Vibeke Trandbohus for technical assistance in the mutation identification process. We thank Jens Joergen Bisgaard for linguistic support, Jan Mohr and Erik Niebuhr for helpful advise over the years, and Jens Rehfeld and Finn Cilius Nielsen for providing laboratory space. The Danish Research Council funded the work.

\section{Authors' affiliations}

M L Bisgaard, The Danish Polyposis Register, Department of Surgical Gastroenterology 435, Hvidovre University Hospital, Hvidovre,

Denmark and Department of Clinical Biochemistry 3011, Rigshospitalet, Copenhagen, Denmark

R Ripa, Department of Clinical Biochemistry 3011, Rigshospitalet, Copenhagen, Denmark

A L Knudsen, S Bülow, The Danish Polyposis Register, Department of Surgical Gastroenterology 435, Hvidovre University Hospital, Hvidovre, Denmark

\section{REFERENCES}

1 Bulow S, Alm T, Fausa O, et al. Duodenal adenomatosis in familial adenomatous polyposis. DAF Project Group. Int J Colorectal Dis 1995; 10:43-6.

2 Knudsen AL, Bulow S. Desmoid tumor in familial adenomatous polyposis. Ugeskr Laeger 2000;162:5628-31.

3 Giardiello FM, Brensinger JD, Petersen GM. AGA technical review on hereditary colorectal cancer and genetic testing. Gastroenterology 2001:121:198-213.

4 Bodmer WF, Bailey CJ, Bodmer J, et al. Localization of the gene for familial adenomatous polyposis on chromosome 5. Nature 1987;328:614-16.

5 Groden J, Thliveris A, Samowitz W, et al. Identification and characterization of the familial adenomatous polyposis coli gene. Cell 1991;66:589-600.

6 Bisgaard ML, Fenger K, Bulow S, et al. Familial adenomatous polyposis (FAP): frequency, penetrance, and mutation rate. Hum Mutat 1994;3:121-5.

7 Kinzler KW, Vogelstein B. Lessons from hereditary colorectal cancer. Cell 1996:87:159-70.

8 Fearnhead NS, Britton MP, Bodmer WF. The ABC of APC. Hum Mol Genet $2001 ; 10: 721-33$.

9 Giardiello FM, Brensinger JD, Petersen GM, et al. The use and interpretation of commercial APC gene testing for familial adenomatous polyposis. N Engl J Med 1997;336:823-7.

10 Groves $C$, Lamlum $H$, Crabtree $M$, et al. Mutation cluster region, association between germline and somatic mutations and genotype-phenotype correlation in upper gastrointestinal familial adenomatous polyposis. Am J Pathol 2002;160:2055-61.

11 Ripa R, Bisgaard ML, Bulow S, et al. De novo mutations in familial adenomatous polyposis (FAP). Eur J Hum Genet 2002;10:631-7.

12 Cooper DN, Ball EV, Krawczak M. The human gene mutation database. Nucleic Acids Res 1998;26:285-7. 
13 Laurent-Puig P, Beroud C, Soussi T. APC gene: database of germline and somatic mutations in human tumors and cell lines. Nucleic Acids Res 1998;26:269-70

14 Caspari R, Friedl W, Mandl M, et al. Familial adenomatous polyposis: mutation at codon 1309 and early onset of colon cancer. Lancet 1994;343:629-32.

15 Dihlmann S, Gebert J, Siermann A, et al. Dominant negative effect of the APC1309 mutation: a possible explanation for genotype-phenotype correlations in familial adenomatous polyposis. Cancer Res 1999:59:1857-60.

16 Heinimann K, Mullhaupt B, Weber W, et al. Phenotypic differences in familial adenomatous polyposis based on APC gene mutation status. Gut 1998;43:675-9.

17 Moisio AL, Jarvinen H, Peltomaki P. Genetic and clinical characterisation of familial adenomatous polyposis: a population based study. Gut 2002; 50:845-50.
18 Laken SJ, Papadopoulos N, Petersen GM et al. Analysis of masked mutations in familial adenomatous polyposis. Proc Natl Acad Sci U S A 1999; 96:2322-6

19 Jones S, Emmerson P, Maynard J, et al. Biallelic germline mutations in MYH predispose to multiple colorectal adenoma and somatic $\mathrm{G}: \mathrm{C} \rightarrow \mathrm{T}: \mathrm{A}$ mutations. Hum Mol Genet 2002;11:2961-7.

20 Sieber OM, Lipton L, Crabtree M, et al. Multiple colorectal adenomas, classic adenomatous polyposis, and germ-line mutations in MYH. N Engl J Med 2003;348:791-9.

21 Stella A, Resta N, Gentile M, et al. Exclusion of the APC gene as the cause of a variant form of familial adenomatous polyposis (FAP). Am J Hum Genet 1993;53:1031-7

22 Crabtree MD, Tomlinson IP, Hodgson SV, et al. Explaining variation in familial adenomatous polyposis: relationship between genotype and phenotype and evidence for modifier genes. Gut 2002;51:420-3.

\section{Clinical Evidence-Call for contributors}

Clinical Evidence is a regularly updated evidence based journal available worldwide both as a paper version and on the internet. Clinical Evidence needs to recruit a number of new contributors. Contributors are health care professionals or epidemiologists with experience in evidence based medicine and the ability to write in a concise and structured way.

\section{Currently, we are interested in finding contributors with an interest in} the following clinical areas:

Altitude sickness; Autism; Basal cell carcinoma; Breast feeding; Carbon monoxide poisoning; Cervical cancer; Cystic fibrosis; Ectopic pregnancy; Grief/bereavement; Halitosis; Hodgkins disease; Infectious mononucleosis (glandular fever); Kidney stones; Malignant melanoma (metastatic); Mesothelioma; Myeloma; Ovarian cyst; Pancreatitis (acute); Pancreatitis (chronic); Polymyalgia rheumatica; Post-partum haemorrhage; Pulmonary embolism; Recurrent miscarriage; Repetitive strain injury; Scoliosis; Seasonal affective disorder; Squint; Systemic lupus erythematosus; Testicular cancer; Varicocele; Viral meningitis; Vitiligo However, we are always looking for others, so do not let this list discourage you.

Being a contributor involves:

- Appraising the results of literature searches (performed by our Information Specialists) to identify high quality evidence for inclusion in the journal.

- Writing to a highly structured template (about 2000-3000 words), using evidence from selected studies, within 6-8 weeks of receiving the literature search results.

- Working with Clinical Evidence Editors to ensure that the text meets rigorous epidemiological and style standards.

- Updating the text every eight months to incorporate new evidence.

- Expanding the topic to include new questions once every 12-18 months.

If you would like to become a contributor for Clinical Evidence or require more information about what this involves please send your contact details and a copy of your CV, clearly stating the clinical area you are interested in, to Claire Folkes (cfolkes@bmigroup.com).

\section{Call for peer reviewers}

Clinical Evidence also needs to recruit a number of new peer reviewers specifically with an interest in the clinical areas stated above, and also others related to general practice. Peer reviewers are health care professionals or epidemiologists with experience in evidence based medicine. As a peer reviewer you would be asked for your views on the clinical relevance, validity, and accessibility of specific topics within the journal, and their usefulness to the intended audience (international generalists and health care professionals, possibly with limited statistical knowledge). Topics are usually 2000-3000 words in length and we would ask you to review between 2-5 topics per year. The peer review process takes place throughout the year, and our turnaround time for each review is ideally 10-14 days.

If you are interested in becoming a peer reviewer for Clinical Evidence, please complete the peer review questionnaire at www.clinicalevidence.com or contact Claire Folkes(cfolkes@bmigroup.com). 